\title{
Is police-public health collaboration an oxymoron?
}

Cite as: CMAJ 2017 May 29;189:E760-1. doi: 10.1503/cmaj.1095431

W hen asked to participate in a panel discussion called "Integrating policing and public health," Dr. Mark Tyndall, executive medical director of the British Columbia Centre for Disease Control, couldn't help but wonder why he, of all people, was invited.

"Actually, I think it's an oxymoron to put these things together," Tyndall said at the session, part of Canada's Drug Futures Forum, held in Ottawa in April. "These are diametrically opposed concepts when it comes to policy."

Not everyone is as pessimistic about police-public health collaborations. In some countries, these collaborations are common and even supported by dedicated institutions. Australia, for example, has the Centre for Law Enforcement and Public Health. According to its director, Nick Crofts, there are dozens of international examples of successful collaborations in areas such as domestic violence, HIV, alcohol abuse and road trauma.

"Collaborations between police and public health can work, do work and are working across the widest range of issues," said Crofts. "There is much more to be done to improve collaborations, but there is no doubt that they work and that outcomes for both sectors are vastly improved when complex issues are approached in partnership."

In the area of illicit drug use, however, it has been particularly challenging to integrate policing and public health, said Tyndall, because the two sides bring such different perspectives to the issue. Police are charged with enforcing laws that consider importing, dealing and using these drugs to be crimes worthy of punishment. Public health, on the other hand, is charged with optimizing people's health and addressing addiction, racism, pov- erty, violence and other issues that lead to poor health outcomes.

According to Tyndall, the problems caused by illicit drug use belong firmly in the realm of public health and social policy. He noted that representatives from law enforcement would never be invited to a conference about improving access to clean drinking water or boosting coverage of childhood vaccines, and yet they often speak on addiction simply because governments have decided that some drugs should be illegal.

"The severely traumatized people that I see do not need policing at all," said Tyndall. "In fact, their day-to-day lives and prospects for recovery are made far worse by criminal sanctions. I have yet to meet anyone who has stopped using drugs because they were arrested or served time."

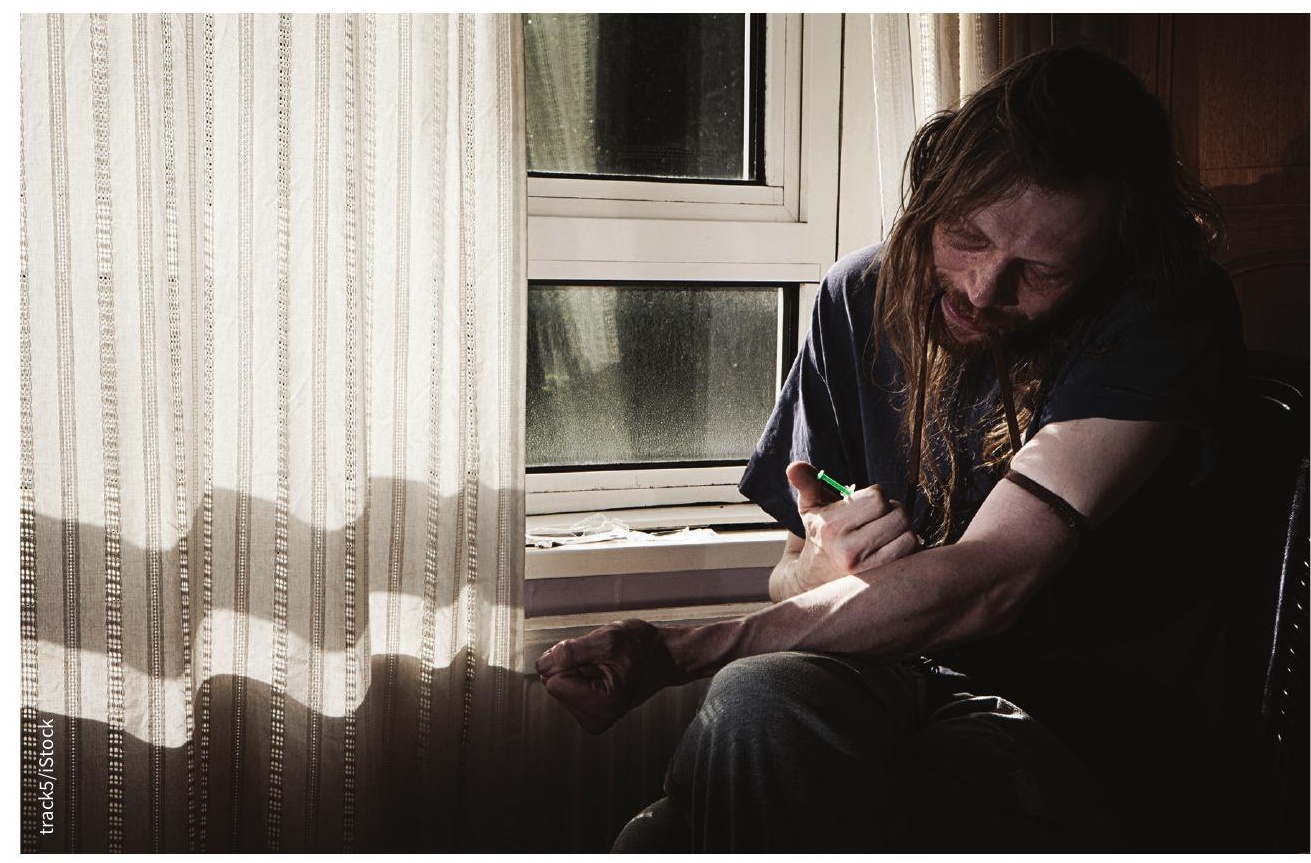

Some public health advocates say aggressive policing of people with addictions does more harm than good.
Tyndall has been involved in harm reduction for people with drug addictions for two decades. There is no more fitting issue for public health than drug abuse and its surrounding consequences, he said. "Unfortunately, as with law enforcement, the public health approach to drug use has also been a massive failure," said Tyndall. "We just haven't wasted as much public resources as law enforcement."

The problem of drug abuse and overdose may be a particularly vexing one, but there are other societal issues that have been dramatically improved through partnerships between public health and law enforcement, according to Crofts. A "classic example" is how to respond to someone experiencing a mental health crisis, he said. Too often these situations were handled only by police with no mental health training and 
resulted in tragedies. Now jurisdictions in many countries have mental health workers respond with police to these incidents. The officers secure the scene and protect the public, and the health workers settle the patient.

In Amsterdam, Crofts noted, the police learned that attempts to transport these patients to places of safety in police cars actually caused the situation to escalate. Now the police force owns ambulances dedicated solely for transporting people experiencing mental health emergencies.

"Safety and security are prerequisites for physical and mental health; both sectors have a commitment to achieving these," said Crofts. "They deal with different aspects of the same complex issues and they do come into conflict time to time, but when they sit down to create a partnership based on respect for each other's role, more often than not both benefit from the experience."

But having a mental health crisis is not a crime, and when illegal activity is involved, the nature of partnerships between health workers and police officers can change, which brings us back to illicit drugs. If one side is focused on punishing people for using drugs, rather than helping them, it can impede access to health services, according to Richard Elliott, executive director of the Canadian HIV/AIDS Legal Network. Any approach that aggressively targets an already marginalized population is not a healthfriendly one, he said.

"An overemphasis on criminalizing, prosecuting and imprisoning people for activities related to drugs generally produces more harm than good to public health," said Elliott.

Discussions of collaboration between public health and law enforcement must be approached very carefully, according to Elliott. Information about individual drug users held by public health workers, for instance, should not be shared with law enforcement, because that could lead to perceptions that public health surveillance is being used to criminalize people, which would undermine efforts to help them.

If the problem at hand is primarily a public health issue, the role of police should be minimal, said Elliott, and in some cases their priority should be "simply to get out of the way."

Not everyone, however, thinks police departments should have such a narrow role in public health matters. Enforcing laws and keeping public order is only a small part of police work, according to Auke J. van Dijk, a senior strategist for Dutch Police Service in Amsterdam. Police departments play a major role in handling many urgent societal issues, which makes collaboration with public health inevitable. The overall goal of both parties is to protect the public and minimize harm to at-risk individuals. There is a constant risk, however, that both sides will "fall back" to their traditional roles instead of putting in the work necessary to achieve the added value of collaboration, he said.

"I am convinced that holistic models of community safety and well-being are the future, and I know many professionals from both sectors agree," said Dijk. "It requires, however, systemic change as well, which probably will not be a linear process."

Roger Collier, CMAJ 